\title{
Recommendations for the compilation of glacier inventory data from digital sources
}

\author{
F. PAUL, ${ }^{1}$ R.G. BARRY, ${ }^{2}$ J.G. COGLEY, ${ }^{3}$ H. FREY, ${ }^{1}$ W. HAEBERLI, ${ }^{1}$ A. OHMURA, ${ }^{4}$ \\ C.S.L. OMMANNEY, ${ }^{5}$ B. RAUP, ${ }^{2}$ A. RIVERA, ${ }^{6}$ M. ZEMP ${ }^{1}$ \\ ${ }^{1}$ Department of Geography, University of Zürich-Irchel, Winterthurerstrasse 190, CH-8057 Zürich, Switzerland \\ E-mail: frank.paul@geo.uzh.ch \\ ${ }^{2}$ National Snow and Ice Data Center, CIRES, University of Colorado, \\ Boulder, CO 80309-0449, USA \\ ${ }^{3}$ Department of Geography, Trent University, Peterborough, Ontario K9J 7B8, Canada \\ ${ }^{4}$ Institute for Atmospheric and Climate Science, ETH Zürich, CH-8092 Zürich, Switzerland \\ ${ }^{5} 56$ Spinney Road, PO Box 730, R.R. \#1, Glenwood, Yarmouth County, Nova Scotia BOW 1W0, Canada \\ ${ }^{6}$ Centro de Estudios Cientificos, Av. Arturo Prat 514, Casilla 1469, Valdivia, Chile
}

\begin{abstract}
Modern geoinformatic techniques allow the automated creation of detailed glacier inventory data from glacier outlines and digital terrain models (DTMs). Once glacier entities are defined and an appropriate DTM is available, several methods exist to derive the inventory data (e.g. minimum, maximum and mean elevation; mean slope and aspect) for each glacier from digital intersection of both datasets. Compared to the former manual methods, the new grid-based statistical calculations are very fast and reproducible. The major aim of this contribution is to help in standardizing the related calculations to enhance the integrity of the Global Land Ice Monitoring from Space (GLIMS) database. The recommendations were prepared by a working group and also contribute to the European Space Agency project GlobGlacier. The document follows the former UNESCO manual for the production of the World Glacier Inventory published in 1970, identifies the potential pitfalls, and describes the differences from the former methods of compilation. The online background material for this paper (see http://www.glims.org) contains example scripts for calculation of each parameter and will be updated when required.
\end{abstract}

\section{INTRODUCTION}

The guidelines outlined here are designed to help in the efficient compilation of glacier inventory data from digital sources (vector outlines, digital terrain models (DTMs)) according to the standards set in the former UNESCO manual (UNESCO/IASH, 1970). This idea was suggested by A. Ohmura at the Workshop on World Glacier Inventory that took place in Lanzhou, China, in September 2008. A small group of experts involved in former and current glacierinventory efforts was nominated to draft the recommendations. The initial focus is on the basic glacier parameters to be compiled. The importance of such compilations is growing in response to the need for regional to global assessments of climate-change impacts, today involving new approaches and advanced technologies. Where more detailed information is available (e.g. the primary classification of glacier type), those data should be included.

In this context, the term 'glacier' refers to all types of glaciers (e.g. valley, mountain, cirque) as well as to ice caps and icefields. The two continental ice sheets of Antarctica and Greenland, as well as their outlet glaciers and ice shelves, are not considered here. Certain parts of the original recommendations (UNESCO/IASH, 1970; Müller and others, 1977) no longer apply, as techniques have changed (e.g. punch cards are no longer in use), the source material is now digital and the main focus is now on climate-change impacts. This has motivated the decision to compile a new set of recommendations.

The most important changes in this document, compared to the former UNESCO manual for the production of the World Glacier Inventory (WGI), are due to the availability of modern data-processing techniques, such as Geographic Information Systems (GIS). In part, the applied methods result in parameters that differ from those obtained previously and thus cannot be compared directly (Manley, 2008). The second important difference is that two-dimensional (2-D) glacier outlines in a digital vector format are now used in addition to the point information available in the former inventory (WGMS, 1989). The related format specifications have been developed within the framework of the Global Land Ice Measurements from Space (GLIMS) initiative (Raup and others, 2007), and a database that stores the information is maintained at the US National Snow and Ice Data Center (NSIDC) in Boulder, CO, USA.

While the 2-D outlines strongly facilitate assessment of glacier changes, rules have to be applied that allow the clear identification of glacier entities independent of the geographic region or the data source (e.g. aerial photography or satellite imagery). These rules have been compiled in the 'GLIMS Analysis Tutorial' (B. Raup and S.J.S. Khalsa, www.glims.org/MapsAndDocs/guides.html) and thus are not discussed here. Further documents describing methods for the automated mapping of glacier outlines from optical satellite data are in preparation. Practical recommendations for glacier mapping are given by Racoviteanu and others (2009). A comprehensive overview of the World Glacier Monitoring Service (WGMS) database was given by WGMS (2008), and a review of the available WGI data is given by Cogley (2009). 


\section{PERENNIAL SNOW AND ICE MASSES TO BE REGISTERED}

In principle, all perennial snow and ice masses should be compiled for a glacier inventory irrespective of size, debris cover, type or other factors. This implies that imagery acquired at the end of the ablation period or dry season is preferred, i.e. without seasonal snow outside the glaciers. To achieve this, every effort should be made to screen the available images and select only the best scenes for glacier mapping, even when parts of them are cloud-covered. However, in some regions it might be difficult to find even a single scene that is free of seasonal snow outside the glaciers. From a practical point of view, it can be very difficult to discriminate between seasonal and perennial snow on a single (satellite) image. As errors are large when seasonal snow is mapped instead of perennial snow or glaciers, a first general recommendation is to identify and mark all snowfields that do not show any bare ice at all. When possible, multitemporal analysis is recommended to separate seasonal snow from perennial snow or glaciers.

It has been recognized from previous studies that human, as opposed to automated, delineation of glacier outlines tended to digitize only a subset of all glaciers in a region, in general the largest ones. This can lead to biased size class distributions and may hide important information about ongoing changes, as in many regions the smallest glaciers may exhibit the strongest changes and can make a significant contribution to the total change (e.g. Paul and others, $2004 \mathrm{~b}$ ). The second recommendation is thus to use one of the many simple, but robust, automated mapping techniques (e.g. band ratios) to map the entire glacier sample and then use manual delineation to correct this classification (e.g. for water bodies, debris cover, shadow, snowfields, and ice on water). Further details are given by Raup and Khalsa (www.glims.org/MapsAndDocs/guides.html) as well as Racoviteanu and others (2009). A manual deselection of seasonal snowfields or any unclear region should also be performed.

The minimum size of the glaciers was not defined consistently for the existing inventories. For example, the inventory of glaciers in Svalbard recorded only ice bodies larger than $1 \mathrm{~km}^{2}$ (WGMS, 1989). In the Alps, with a different size distribution, $90 \%$ of the glaciers would have been left out according to this rule. On the other hand, a size of $0.01 \mathrm{~km}^{2}$ could be seen as a practical lower limit, as entities smaller than this can be very numerous and their status as glaciers is likely to be doubtful. This is also the minimum size that can be identified with certainty under good conditions from satellite sensors operating at 15-30 m spatial resolution (e.g. Terra Advanced Spaceborne Thermal Emission and Reflection Radiometer (ASTER), SPOT High Resolution Visible (HRV), Landsat Thematic Mapper (TM)/ Enhanced TM Plus (ETM+)). It is thus recommended that $0.01 \mathrm{~km}^{2}$ be used as the minimum size to be registered when conditions permit. This small size is also important for following temporal developments. Entities that were much larger in a previous inventory might have shrunk to this size or to several patches of this size. In the latter case, the total size of the remaining ice bodies could again be larger than $0.01 \mathrm{~km}^{2}$. Also, from a statistical point of view, it is necessary to make the comparison against some value rather than none.

\section{SOURCE MATERIAL}

For the application of the methods presented here, we assume that digital glacier outlines (i.e. individual entities including their debris-covered parts rather than contiguous ice masses) and a DTM are available. While the sources of the outlines and DTM are not prescribed, both should have been acquired within the same decade, and the spatial resolutions of both datasets should be comparable. The metadata of the source material are stored separately in the GLIMS database (B. Raup and S.J.S. Khalsa, 'A method for transferring GLIMS analysis products from regional centers to NSIDC. Version 1.2', www.glims.org/MapsAndDocs/). Within the framework of the Global Terrestrial Network for Glaciers (GTN-G), the use of satellite data is highly recommended for the compilation of glacier inventory data. This has the advantage of covering large areas at the same time, of permitting automated mapping from multispectral sensors and of an appropriate spatial resolution for the target. However, glacier outlines digitized from topographic maps of sufficient quality and detail can also be used.

For a thorough description of the related digitizing work, refer to Fountain and others (2007). When working with satellite data at $15-30 \mathrm{~m}$ resolution, the DTM should optimally have the same resolution. However, a DTM with $100 \mathrm{~m}$ resolution can still be used for glaciers at least $0.1 \mathrm{~km}^{2}$ in size, which corresponds to 10 pixels at $100 \mathrm{~m}$. In regions with rapid and strong glacier changes, the DTM should be no more than 5-10 years older than the satellite scene to avoid wrong topographic parameters such as minimum elevation. In any case, inclusion of the date of the DTM will be mandatory.

For a global glacier inventory it would be ideal to use the same satellite sensor, year of data acquisition, DTM, mapping method and classification guidelines for all countries. Because this is not feasible, it is difficult to make general recommendations. However, as some countries might be able to follow a common guideline in this regard, we summarize a few points (input data, method, date) that should help create a more consistent global glacier inventory.

In view of the free availability of Landsat data from the US Geological Survey archive, the Shuttle Radar Topography Mission (SRTM) DTM from 2000 at about $90 \mathrm{~m}$ resolution (void filled from http://srtm.csi.cgiar.org/), the new ASTER global DEM (GDEM) and the well-established automated mapping methods such as band ratios with a threshold, the following recommendations can be made:

Landsat ETM+ or TM data from the year 2000 ( \pm 5 years) should be used. In regions with tiny glaciers, ASTER scenes may be preferable.

The void-filled version of the SRTM3 DTM version 4 (A. Jarvis and others, http://srtm.csi.cgiar.org/PDF/Jarvis4. pdf) or the new global ASTER GDEM (Hayakawa and others, 2008) should be used.

A thresholded band ratio (e.g. TM3/TM5 or ASTER 2/4) with an additional threshold in band 1 of each sensor for improved shadow mapping should be used for automated glacier delineation (clean ice). Regions of misclassification (lakes, debris cover, shadow, seasonal snow, ice on water) should be corrected manually. For mapping of lakes and debris cover, semi-automated methods have been proposed in the literature (e.g. 
Huggel and others, 2002; Paul and others, 2004a; Bolch and others, 2007), which can help with the correction.

The published guidelines for determining glacier entities (Raup and Khalsa, www.glims.org/MapsAndDocs/ guides.html) and calculation of glacier parameters as given in this document should be followed.

In view of the rapid technological developments (new sensors or data sources), it is expected that the global picture of glaciers and ice caps will become more and more complete. In particular, updated glacier inventories and related change assessments will increasingly become available for different parts of the world. In this respect, it is paramount to have methodological coherence in the derived datasets. Future sensors might permit calculation of additional relevant glacier parameters or the development of operational glacier monitoring. Such opportunities will be described in forthcoming documents.

\section{DATA ORGANIZATION}

In order to accomplish a global glacier inventory quickly (Casey, 2003), a restriction to a minimum set of glacier parameters that can usually be generated automatically is recommended. This minimum set should be included in each compilation and consists of 12 elements: identification (ID), $x-y$ coordinates, date, surface area, length, minimum, maximum, mean and median elevation, as well as mean orientation and slope (see below for details). For the GLIMS database, the date of each dataset analysed (e.g. related to the acquisition date of a satellite scene) is a mandatory part of the submission and can automatically be transferred to all analysed glaciers. Their surface area can also be calculated automatically in the database. Apart from length, the values for all parameters can be derived with automated GIS-based calculations which are assumed to be precise and objective. A general rule for the records in a database is that only quantities are stored that are not derived from the entries in the database. For example, the midpoint elevation, calculated as minimum plus maximum elevation divided by two, will not be reported, while the mean elevation as derived from DTM statistics will be included. Elevation range is minimum minus maximum elevation and thus is also not included in the database.

Apart from this minimum set, a large number of additional items are useful, but not mandatory for fast delivery; some require manual work, while others can be derived automatically. The former group includes: glacier name, national inventory code, former WGI code or hydrologic unit, debris-free surface area, primary classification (glacier type) and elevation of the snowline. The latter group includes: local ID, country code, hypsography in $100 \mathrm{~m}$ elevation bins, and elevations for certain area ratios. The latter are frequently used for modelling purposes (e.g. Haeberli and Hoelzle, 1995; Maisch and others, 2000; Hoelzle and others, 2007; Paul and others, 2007) because the elevation referring to a certain ratio (e.g. a $2: 1$ or $67 \%$ accumulation-area ratio (AAR)) can be used as a proxy for the steady-state equilibrium-line altitude $\left(E^{2} A_{0}\right)$ (e.g. Gross and others 1977). A recent study by Bahr and others (2009) indicates that a $1.5: 1$ ratio $(60 \%$ AAR) fits better to the global mean value (59\%).

Elevations can be derived automatically for each glacier using the original DTM, and one of the elevation ratios can be used to separate a glacier in an accumulation and ablation region to derive some quantities (e.g. length, aspect) specifically for these regions, as in the former WGI. Thus, apart from the median elevation or $1: 1$ area ratio, the elevation corresponding to the $2: 1$ area ratio might also be reported. This would cover the typical range of measured values (e.g. WGMS, 2008) around a mean, and facilitate upper/lower bound modelling. In the end, it will be up to the analyst to decide which additional items are included in the submission. The data formats for most of the parameters are prescribed by the GLIMS data transfer specification (Raup and Khalsa, www.glims.org/MapsAndDocs/).

In this regard it is important to note that the elevation of the snowline as visible on the satellite imagery is only a proxy for the ELA of that specific year and only when image acquisition was close to the end of the ablation period. In Arctic regions, there is often a considerable difference between the elevation of the snowline and the ELA, as the superimposed ice zone is difficult to distinguish from bare ice on satellite imagery. This kind of annually highly variable information thus belongs to a fluctuation data series rather than to an inventory. Indeed, transient snowline positions were listed in the former WGI and have been used to derive further quantities. However, as detailed above, the quantities relevant for modelling with inventory data should be based on hypsographic area ratios which are more characteristic for the long-term status of glaciers (e.g. Furbish and Andrews, 1984).

A special topic is accuracy. The GLIMS glacier database allows the assignment of two accuracy values for each outline segment of a glacier. One is related to the overall positional accuracy of the input dataset (e.g. the root-meansquare error of $x$ and $y$ coordinates of the orthorectification), and the other to the accuracy of the outline delineation. The latter could be much lower in regions with debris cover compared to clean ice, in shadow or for ice-ice divides in flat accumulation areas. As the compilation of this information is time-consuming for individual glacier segments, it is recommended that a fixed accuracy value be applied (e.g. size of one or two image pixels) to all glaciers as a first step for fast data submission. When time permits, further details can be added later to the accuracy item.

All meta-information required for clear identification of the dataset is submitted with the mandatory GLIMS files. These data files include among others information about the satellite scene used (date, path, row, sensor), the classification method applied, the name of the analyst and the date/ region of the analysis, as well as the date, source and spatial resolution of the DTM. Of course, references to be cited, acknowledgements and any other important metainformation can also be submitted (see Raup and Khalsa, www.glims.org/MapsAndDocs/). In the case of a multitemporal composite for a specific region, the acquisition dates for each glacier entity are particularly important.

\section{ADDITIONAL INFORMATION}

There are several parameters of great practical use that can be calculated from the basic inventory entries and would thus not be part of the database. However, to ensure some consistency in the calculation, we also include the calculation for the orientation in eight sectors here. For a few glaciers, mean thickness values are available from extrapolated field measurements. They can be listed in the 

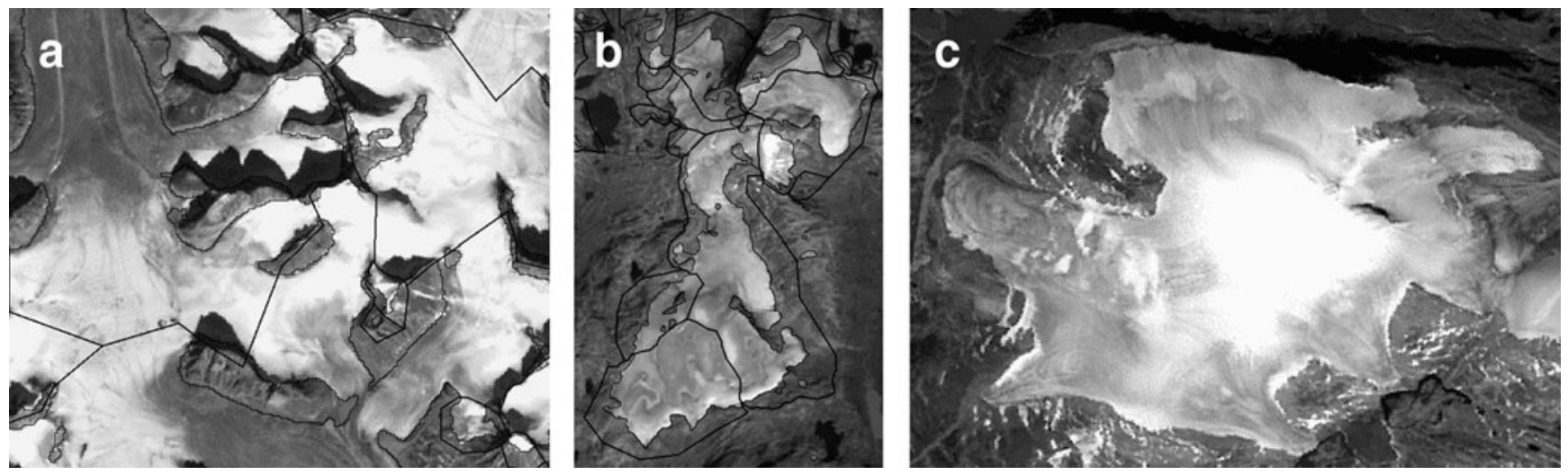

Fig. 1. (a) Uncertain drainage divides (estimated by straight lines) in the accumulation area of glaciers due to a missing DTM. The region is located near Penny Ice Cap, Baffin Island, Canada, and acquired by Landsat ETM+ (17-13) on 13 August 2000. (b) A compound glacier (Harbardsbreen) near Jostedalsbreen, Norway, as seen with Landsat TM (201-17) on 16 September 2006. Individual glaciers have been separated using a DTM. (c) A small ice cap with radial flow on Baffin Island as seen with Landsat ETM+ (21-11) on 30 July 2002 . In this case the entire ice mass will be treated as one entity. Seasonal snow hides a part $(<5 \%)$ of the perimeter.

'point_measurements' table of the GLIMS database. As part of the GTN-G database integration, it is planned to provide a joint map interface and a corresponding look-up table which link the available data from the WGMS, WGI, GLIMS and NSIDC photograph collection. This should allow easy access to mass-balance data or volume/length-change measurements.

A further point suggested here for the first time is a new 'remarks' item in the GLIMS database that gives a unique four-digit code for rapid identification of specific glacier characteristics (Table 1). This allows for an efficient selection or deselection of such special glaciers in global assessments. The numbering scheme follows that used in the WGI for the morphological classification of glaciers with one digit per item and considers the items snow conditions, calving, surging and ice divides. A basic intention of the reduced number of codes is to keep the scheme simple in order to facilitate its wide application. The digit 0 indicates that none of the criteria apply to a specific glacier and everything is normal, 8 is assigned to indicate that special remarks are given elsewhere for this item, and 9 is given as the default when the item is not classified. The unused numbers for each item are reserved for later extensions. Hence, in the default case, the remarks item has the code 9999 and if everything is normal 0000 which is numerically equivalent

Table 1. Codes for the four digits of the new remarks column in the GLIMS glacier database. Abbreviations: perim.: perimeter; spec. rem.: see specific remarks; not spec.: not specified

\begin{tabular}{lcccc}
\hline Code & 1: Snow & 2: Calving & 3: Surging & 4: Divides \\
\hline 0 & $\begin{array}{c}\text { normal } \\
\text { hides 5-50\% of } \\
\text { perim. }\end{array}$ & $\begin{array}{c}\text { normal } \\
\text { tidewater }\end{array}$ & $\begin{array}{c}\text { normal } \\
\text { reported }\end{array}$ & $\begin{array}{c}\text { normal } \\
\text { uncertain }\end{array}$ \\
& $\begin{array}{c}\text { hides }>50 \% \text { of } \\
\text { perim. }\end{array}$ & freshwater & signs & compound \\
3 & perennial snowfield & dry & signs \& reported & ice cap \\
4 & $\begin{array}{c}\text { seasonal snowfield } \\
\text { spec. rem. }\end{array}$ & $\begin{array}{c}\text { regenerated } \\
\text { spec. rem. }\end{array}$ & $\begin{array}{c}\text { spec. rem. } \\
\text { not spec. }\end{array}$ & $\begin{array}{c}\text { spec. rem. } \\
\text { not spec. }\end{array}$ \\
\hline & not spec. & not spec. & not spec.
\end{tabular}

to 0 . If the code is larger than 0 but less than 10, something is special about the basin divides, and so forth. For example, a tidewater glacier with signs of surging (e.g. looped moraines) and uncertain drainage divides would receive the code 0121 (numerically equal to 121); or a (mainly) drycalving ice cap where $20 \%$ of the perimeter is covered by seasonal snow would receive the code 1303 .

In Figure 1 some examples for glaciers which would be coded 1, 2 or 3 in the remarks column (i.e. special ice divides) are illustrated. Code 1, 'uncertain', is depicted in Figure 1a showing digitized straight lines in the snowcovered accumulation area of several adjacent glaciers. In this case, a DTM was not available and a lack of contrast prevents the location of the divide from being identified (Paul and Kääb, 2005). Similarly, a poor-quality DTM might not reveal the location properly and code 1 can be assigned to the related glaciers. A compound glacier (code 2) is an ice mass that is a composite of several individual glaciers (Fig. 1b) without the radial flow required for an ice cap. It is divided into individual entities, although the location of the divides might not be certain (Andreassen and others, 2008). On the other hand, an ice cap (code 3) has some sort of radial flow from one or more centres and is treated as one entity without divides (Fig. 1c).

When codes for the second and third digits are given, the derived topographic parameters (e.g. minimum or mean elevation) might be very different from those of neighbouring glaciers and should be excluded from the related statistical calculations. Problems related to glacier identification due to snow cover can be indicated with the first digit. Apart from debris cover, seasonal snow introduces the most serious problem for correct glacier delineation and thus has the highest number (1000 and larger). Whether a snowfield is seasonal or perennial can only be determined by multitemporal image analysis.

\section{BASIC PARAMETERS}

\subsection{General remarks}

In the compilation below, a description and a definition of each parameter is provided, including the description of the GIS-based method of calculation. Differences from the previous inventory guidelines are also given. In Table 2, all 
parameters are listed including a link to their calculation as given in the appendix of the online background material for this paper. The source codes are only given in that document to exemplify and better illustrate the manner of calculation. In the following, it is assumed that the newly created glacier inventory is the first one. The comparison of data from repeat inventories from two or more points in time and the related calculation of changes in any of the parameters will be addressed in forthcoming documents.

\subsection{Identification/code}

Each glacier entity must have a unique identification code. In the former guide this code was related to the political state and hydrological unit of major and lower-order streams. In the GLIMS database a unique code is generated (GLIMS-ID) from the geographic coordinates of the glacier. Automated scripts for generating the code from the geographic coordinates (latitude, longitude) of the glacier exist (see appendix 1 in the online background material). A point to consider is that a coordinate transformation must be applied to convert the coordinates of the finally assigned glacier entities from the projected coordinate system (e.g. Universal Transverse Mercator (UTM)) used for the analysis to geographic coordinates with the World Geodetic System 1984 (WGS84) datum before they can be converted to the GLIMS-ID. Also, all glacier outlines are stored in longitude/ latitude coordinates in the GLIMS glacier database.

\subsection{Coordinates}

The coordinates should describe the location of a glacier as accurately as possible. In the former WGI it was recommended to place this point in the upper part of the ablation area near the centre of the main stream. This recommendation is still valid for manual assignment of the coordinates. Considering the available GIS-based methods, it is also acceptable to create a label point inside a glacier polygon automatically, and add the $x-y$ coordinates of this point to the attribute table of the respective glacier (see example script in appendix 1 of the online background material). While this automated assignment is fast, it has to be noted that internal polygons might also receive a label point (depending on the software used) and these have to be replaced with the ID of the surrounding glacier. In general, the label point will be located somewhere inside the polygon, maybe very close to the outline of the glacier. As long as the number of digits for each geographical coordinate is sufficient to separate the labels of two adjacent glaciers, this is in general straightforward. The number of digits for the GLIMS ID is fixed.

In regions where glacier changes are small and the coordinates from a former glacier inventory are available, it should be determined whether the former coordinates are still within the current outlines. If they have been stored with a sufficient number of digits, it is possible that only a few label points have to be shifted slightly. This way of assigning label points is preferable in order to establish a link to the former inventory.

\subsection{Date}

Each glacier outline has to be associated with the date of its acquisition, if possible day, month and year. This can be done automatically for all glacier entities under consideration in a GIS. Special care is required when multitemporal data are used in the same region. For submission of results to
Table 2. Basic glacier parameters that should be provided with each GLIMS submission. For the scripts that describe the calculation of each parameter refer to appendixes 1 and 2 of the online background material

\begin{tabular}{lccc}
\hline Name & Item & Symbol & Script \\
\hline Code (GLIMS-ID) & ID & ID & App. 1 \\
Coordinates & x_coord, y_coord & $\mathrm{x}, \mathrm{y}$ & Automatic \\
Acquisition date & Date & date & Automatic \\
Surface area & Area_km2 & $\mathrm{S}$ & Automatic \\
Length (max.) & Length & $\mathrm{I}_{\max }$ & Manual \\
Minimum elevation & Min & $\mathrm{h}_{\min }$ & App. 2 \\
Maximum elevation & Max & $\mathrm{h}_{\max }$ & App. 2 \\
Mean elevation & Mean & $\mathrm{h}_{\operatorname{mean}}$ & App. 2 \\
Median elevation & Median & $\mathrm{h}_{\text {medi }}$ & App. 2 \\
Mean slope & Slope_deg & a & App. 2 \\
Mean aspect & Aspect_360 & $\phi_{360}$ & App. 2 \\
Aspect sector & Aspect_sec & $\phi_{\text {sec }}$ & App. 2 \\
\hline
\end{tabular}

the GLIMS database, the date of the analysed glacier outlines is a mandatory part in a separate file and is automatically linked to each outline.

\subsection{Total surface area}

The surface area of a glacier is an important parameter because it is used in many applications including global upscaling of glacier properties. It is thus recommended that the Raup and Khalsa tutorial (www.glims.org/MapsAndDocs/guides.html) be followed for defining individual glacier entities. Once this has been done, a GIS can automatically write the area and perimeter of the glacier polygon to the attribute table. It is important that glacier area is measured in an appropriate metric projection. The value should be recorded in square kilometres with three digits after the decimal point. This precision facilitates sorting glaciers into logarithmic (base 2) size classes in subsequent analysis.

For the transfer to the GLIMS database it is important that all polygons which are internal to a specific outer polygon are labelled as 'intrnl_rock' and that they have the same GLIMS-ID as the surrounding glacier, and are not simply represented as 'holes' in the outer polygon. On the other hand, rock outcrops shared by more than one glacier (called shared polygons) have no GLIMS-ID (Raup and Khalsa, www.glims.org/MapsAndDocs/guides.html), as they are not internal to any glacier polygon. There is a so-called flattening tool available on the GLIMS website that can be used to convert polygon holes that represent internal rock outcrops to polygons with appropriate GLIMS glacier IDs (http://glims.colorado.edu/tools/).

\subsection{Length}

Glacier length is the most demanding parameter regarding additional manual work and uncertainty. The definitions used in the former guide are:

Mean length: The average of the lengths of each tributary along its longest flowlines to the glacier snout.

and

Maximum length: The longest flowline of the whole glacier. 
These definitions still apply and it is recommended that initially only the maximum length be determined, as this reduces the workload considerably. The mean length could be added in a later step. When a DTM of sufficient quality is available, automated techniques can be used to identify the highest glacier point and then follow the steepest downward gradient until the curvature of the glacier surface changes from concave to convex. In this region - in general, the ablation area - manual digitization close to the central flowline of the main trunk might be more efficient. For manual digitization of the length, the flowline should cross elevation contours perpendicularly. Uncertainty of the result is thereby reduced if flowline digitization starts at the lower end of the glacier.

\subsection{Elevation (max, min, mean, median)}

Highest, mean and lowest glacier elevation are also basic entries in the former WGI. It is recommended that they be derived from glacier-specific statistical analysis using the elevation information from the DTM and a local glacier ID as an identifier for the respective glacier or zone. The related script for calculation is given in appendix 2 of the online background material for this paper. It has to be noted that in the former inventory mean elevation was defined as the elevation of 'The contour line which divides the glacier surface in half, which is identical with the hypsographic $1: 1$ area ratio or median elevation. The mean value derived from zone statistics will represent a different value: the sum of all elevation values divided by the number of all cells used for the sum. This is different from the midpoint elevation and should thus be included in the inventory. The median elevation as calculated from area statistics represents the correct $1: 1$ elevation and should also be included.

\subsection{Mean aspect}

The aspect or orientation of a glacier is a useful parameter for all kinds of modelling (e.g. Evans, 2006). In the former UNESCO guidelines this variable was restricted to eight directions: 'Orientation of the down-glacier direction according to the eight cardinal points ... should be given.' The mean aspect as derived from a DTM allows one to consider the value of all individual cells covered by the glacier and to derive a mean value in the full $0-360^{\circ}$ range. It must be taken into account that aspect is a circular parameter, which means that mean values must be derived by a decomposition in the respective sine and cosine values (Paul, 2007; Manley, 2008). A script that calculates the correct mean values is given in appendix 2 of the online background material. Apart from the improved detail and the objectivity of its calculation, the DTM-derived value also has a slightly different meaning than in the former inventory (e.g. main flow direction vs mean value of individual cells). The value could also be calculated separately for the accumulation and ablation region once they are defined and transformed to the eight cardinal directions.

\subsection{Mean slope from the DTM}

Mean slope is a value that could be derived from elevation range and glacier length and was thus not listed in the guidelines by UNESCO/IASH (1970). Mean slope as derived for each glacier from the DTM with zone statistics is independent of the glacier length and refers to all individual cells of the DTM (Manley, 2008). As mean slope is a good proxy for other parameters like mean thickness (Haeberli and Hoelzle, 1995) it is recommended that the DTMderived mean slope value be included in the basic inventory.

\subsection{Derived quantities}

A large number of further parameters characterizing individual glaciers (e.g. driving stress, slope-dependent thickness, volume, thermal conditions, response and reaction times) can be derived or estimated from the basic parameters described above and in combination with climatic data as demonstrated in the case study for the European Alps by Haeberli and Hoelzle (1995). For details of their calculation the reader is referred to that publication.

\section{FURTHER PARAMETERS}

As mentioned in section 4, several further parameters exist that could be included in a glacier inventory, but their compilation is time-consuming and the entries are not mandatory for a fast submission. These parameters are briefly described in the following.

\subsection{Glacier name}

The glacier name facilitates discussion of the glacier, but is not unique. Where an official name of the main glacier is available, it should be provided. If no official name has been assigned, only a well-established unofficial name should be given. Meaningful abbreviations are allowed for very long names. The spelling of the name should be in the Latin alphabet without special characters. The local word for 'glacier' (e.g. Firn, Kees, Gletscher in the Alps) should be retained where it is an integral part of the name such as in Storbreen and Storglaciären. If a glacier has more than one common name, a list of names may be provided, separated by commas.

\subsection{WGI code or hydrologic unit}

All glaciers with an entry in the former WGI should have a WGI code as a unique identifier. Where available, this code should be transferred to the new inventory. Moreover, major hydrological units and river systems have been identified on all continents (WGMS, 1989) and can be applied to previously unregistered units. The recommended clockwise numbering of the entities should be maintained. Problems of identifying the correct WGI code for more recent entities are related to:

the former assignment of glacier groups (only one code available for several glaciers, partly located in different drainage basins),

separate codes having been given to tributaries still connected to the main glacier,

only one code being available for a contiguous ice mass that should be separated into parts,

glaciers having no code at all as they were excluded in the former inventory (e.g. due to snow conditions or clouds),

codes having been given to seasonal rather than perennial snowfields.

All these issues can only be resolved if the generally analogue base maps from the former inventory are available for inspection. In many cases it will be necessary to assign the former code to more than one entity, as many glaciers 
have split into two or more parts in the past 30 years. When this can be done properly, it will help considerably in change assessment. In the GLIMS glacier database the relation to formerly connected glacier entities is addressed by the parent ice-mass code (see Raup and Khalsa, www.glims.org/MapsAndDocs/).

\subsection{Exposed area}

In general, optically thick (in respect to the averaged spectral information of one image pixel) debris cover is not mapped by the spectrally based automated methods. This implies that the debris-free surface area is available from the automated classification and the total area is given after manual correction of the debris-covered parts. Both values could be given when multispectral classification is used for glacier mapping.

\subsection{Local ID}

For practical reasons it is useful to work with a unique local ID for each glacier entity. This code should be a simple fouror five-digit number which could be assigned automatically to all glaciers. The local ID is particularly helpful when attribute items from external computations have to be joined with the main dataset and when statistics are calculated for each glacier zone.

\subsection{Primary classification (glacier type)}

The primary classification (WGMS, 1989) helps to characterize a glacier sample in more detail. Apart from the fact that the former key has to be extended when polar ice masses are classified (e.g. Cogley, 2008; F. Rau and others, 'Illustrated GLIMS glacier classification manual: glacier classification for the GLIMS inventory. Version 1', www.glims.org/ MapsAndDocs/guides.html), little is known about the practical value of the classification. In particular, the classes are often not unique and different analysts might arrive at different types. When glaciers change rapidly (e.g. due to the formation of proglacial lakes), certain parts of the classification may also change in a short time, so updating the database might become a continuous effort. For this reason, it is recommended that the taxonomical classification be postponed to a later date. Of course, if the classification is available already, it should be submitted as well.

\subsection{Elevation of the end-of-summer snowline}

This parameter is mentioned here because it was compiled in many regions for the WGI. However, in most cases the transient snowline (TSL) was mapped in the WGI, which is of little relevance in glaciologic terms. Only when data are acquired at the end of the ablation period can the elevation of the snowline or the area covered by snow compared to the entire surface area (AAR) be used as a proxy for the mass balance or to assess local differences in accumulation. In this regard, snowlines can be considered as glacier fluctuation data (with strong changes from year to year) that must not be a part of an inventory but can be submitted to the WGMS. From this point of view it is recommended that time be spent on deriving the other parameters first.

\subsection{Hypsography in $\mathbf{1 0 0} \mathrm{m}$ bins}

A new possibility, easily obtained by combining glacier outlines with the DTM, is the calculation of glacier-specific area-elevation distribution or hypsography. Such information would greatly improve the calculation of future glacier response to climate change, as glacier melt as well as precipitation is largely elevation-dependent. A $100 \mathrm{~m}$ binning (or sub-multiple thereof for very small glaciers) is recommended to maintain some consistency in the database and to cover the large range of possible values without losing relevant information for smaller glaciers. While the database transfer specification allows a designation of how elevations of bins are registered, it is recommended that the value for a specific elevation band (e.g. $3800 \mathrm{~m}$ ) should refer to the range of the following $100 \mathrm{~m}$ (here $3800-3900 \mathrm{~m}$ ). This would strongly facilitate the comparability of the created datasets and hence global applications. The GLIMS glacier database includes two tables that store information about the hypsometry dataset as a whole (bin width, etc.) and another that stores the area (in $\mathrm{km}^{2}$ ) in each elevation bin (for details see Raup and Khalsa, www.glims.org/MapsAndDocs/). A script for calculating a 100 m hypsography automatically for each glacier can be found in Paul (2007).

\section{CONCLUSIONS}

We have presented recommendations on how glacier parameters should be calculated for a detailed glacier inventory when digital glacier outlines and a DTM are available. The focus is on parameters that can be compiled automatically for each glacier. Most time-consuming is the manual digitizing of glacier length. Besides the basic parameters, other useful parameters are added for practical purposes. Considering the rapid technological development and the explosion of freely available datasets in the recent past, it is assumed that parts of the recommendations will have to be updated regularly. The online background material for this paper (available at http://www.glims.org) includes example source codes for calculation and will be updated when required.

\section{ACKNOWLEDGEMENTS}

The study was supported by a grant from the European Space Agency project GlobGlacier (21088/07/I-EC). Feedback from the GLIMS community as well as from the GlobGlacier user group and consortium is gratefully acknowledged.

\section{REFERENCES}

Andreassen, L.M., F. Paul, A. Kääb and J.E. Hausberg. 2008. Landsat-derived glacier inventory for Jotunheimen, Norway, and deduced glacier changes since the 1930s. Cryosphere, 2(2), 131-145.

Bahr, D.B., M. Dyurgerov and M.F. Meier. 2009. Sea-level rise from glaciers and ice caps: a lower bound. Geophys. Res. Lett., 36(3), L03501. (10.1029/2008GL036309.)

Bolch, T., M.F. Buchroithner, A. Kunert and U. Kamp. 2007. Automated delineation of debris-covered glaciers based on ASTER data. In Gomarasca, M.A., ed. Geolnformation in Europe. Proceedings of the 27th EARSeL Symposium, 4-6 June 2007, Bolzano, Italy. Rotterdam, Millpress, 403-410.

Casey, A., ed. 2003. Papers and recommendations: Snow Watch 2002 Workshop and Workshop on Assessing Global Glacier Recession, 31 October-1 November 2002, Camp Spring, MD. Boulder, CO, National Snow and Ice Data Center. World Data Center A for Glaciology. (Glaciological Data GD-32.)

Cogley, J.G. 2008. Extended format for the World Glacier Inventory. Revised edition. Peterborough, Ont., Trent University. (Trent Technical Note 2005-1.) 
Cogley, J.G. 2009. A more complete version of the World Glacier Inventory. Ann. Glaciol., 50(53), 32-38.

Evans, I.S. 2006. Local aspect asymmetry of mountain glaciation: a global survey of consistency of favoured directions for glacier numbers and altitudes. Geomorphology, 73(1-2), 166-184.

Fountain, A.G., M.J. Hoffman, K.M. Jackson, H.J. Basagic, T.H. Nylen and D. Percy. 2007. Digital outlines and topography of the glaciers of the American West. USGS Open File Rep. 2006-1340.

Furbish, D.J. and J.T. Andrews. 1984. The use of hypsometry to indicate long-term stability and response of valley glaciers to changes in mass transfer. J. Glaciol., 30(105), 199-211.

Gross, G., H. Kerschner and G. Patzelt. 1977. Methodische Untersuchungen über die Schneegrenze in alpinen Gletschergebieten. Z. Gletscherkd. Glazialgeol., 12(2), 223-251.

Haeberli, W. and M. Hoelzle. 1995. Application of inventory data for estimating characteristics of and regional climate-change effects on mountain glaciers: a pilot study with the European Alps. Ann. Glaciol., 21, 206-212.

Hayakawa, Y.S., T. Oguchi and Z. Lin. 2008. Comparison of new and existing global digital elevation models: ASTER G-DEM and SRTM-3. Geophys. Res. Lett., 35(17), L17404. (10.1029/ 2008GL035036.)

Hoelzle, M., T. Chinn, D. Stumm, F. Paul, M. Zemp and W. Haeberli. 2007. The application of glacier inventory data for estimating past climate change effects on mountain glaciers: a comparison between the European Alps and the Southern Alps of New Zealand. Global Planet. Change, 56(1-2), 69-82.

Huggel, C., A. Kääb, W. Haeberli, P. Teysseire and F. Paul. 2002. Remote sensing based assessment of hazards from glacier lake outbursts: a case study in the Swiss Alps. Can. Geotech. J., 39(2), 316-330.

Maisch, M., A. Wipf, B. Denneler, J. Battaglia and C. Benz. 2000. Die Gletscher der Schweizer Alpen. Gletscherhochstand 1850, Aktuelle Vergletscherung, Gletscherschwund-Szenarien. Zürich, vdf Hochschulverlag AG ETH. (Schlussbericht NFP 31.)

Manley, W.F. 2008. Geospatial inventory and analysis of glaciers: a case study for the eastern Alaska Range. In Williams, R.S., Jr and J.G. Ferrigno, eds. Satellite image atlas of glaciers of the world. Denver, CO, United States Geological Survey, K424-K439. (USGS Professional Paper 1386-K.)
Müller, F., T. Caflisch and G. Müller. 1977. Instructions for the compilation and assemblage of data for a world glacier inventory. Zürich, ETH Zürich. Temporary Technical Secretariat for the World Glacier Inventory.

Paul, F. 2007. The new Swiss glacier inventory 2000: application of remote sensing and GIS. Schr. Phys. Geogr. Univ. Zürich 52.

Paul, F. and A. Kääb. 2005. Perspectives on the production of a glacier inventory from multispectral satellite data in Arctic Canada: Cumberland Peninsula, Baffin Island. Ann. Glaciol., 42, 59-66.

Paul, F., C. Huggel and A. Kääb. 2004a. Combining satellite multispectral image data and a digital elevation model for mapping debris-covered glaciers. Remote Sens. Environ., 89(4), 510-518.

Paul, F., A. Kääb, M. Maisch, T. Kellenberger and W. Haeberli. 2004b. Rapid disintegration of Alpine glaciers observed with satellite data. Geophys. Res. Lett., 31(21), L21402. (10.1029/ 2004GL020816.)

Paul, F., M. Maisch, C. Rothenbühler, M. Hoelzle and W. Haeberli. 2007. Calculation and visualisation of future glacier extent in the Swiss Alps by means of hypsographic modelling. Global Planet. Change, 55(4), 343-357.

Racoviteanu, A.E., F. Paul, B. Raup, S.J.S. Khalsa and R. Armstrong. 2009. Challenges and recommendations in mapping of glacier parameters from space: results of the 2008 Global Land Ice Measurements from Space (GLIMS) workshop, Boulder, Colorado, USA. Ann. Glaciol., 50(53) (see paper in this issue).

Raup, B., A. Racoviteanu, S.J.S. Khalsa, C. Helm, R. Armstrong and Y. Arnaud. 2007. The GLIMS geospatial glacier database: a new tool for studying glacier change. Global Planet. Change, 56(1-2), 101-110.

UNESCO/International Association of Scientific Hydrology (IASH). 1970. Perennial ice and snow masses: a guide for compilation and assemblage of data for a world inventory. Paris, UNESCO/ IASH. (Technical Papers in Hydrology 1.)

World Glacier Monitoring Service (WGMS). 1989. World glacier inventory: status 1988, ed. Haeberli, W., H. Bösch, K. Scherler, G. Østrem and C.C. Wallén. IAHS(ICSI)-UNEP-UNESCO, World Glacier Monitoring Service, Zürich.

WGMS. 2008. Global glacier changes: facts and figures, ed. Zemp, M., I. Roer, A. Kääb, M. Hoelzle, F. Paul and W. Haeberli. UNEP, World Glacier Monitoring Service, Zürich. 